\title{
Development of eco-friendly washing machine
}

\author{
Hamzah Sakidin ${ }^{1 *}$, Pretesh Sudhakaran ${ }^{2}$, Muhammad Syaamil Saad ${ }^{3}$, Sarah Syamimi \\ Rozali $^{4}$, Abdul Hadi Nasarudin ${ }^{5}$ and Ahmed Abdullah AlMashhor ${ }^{6}$
}

\author{
${ }^{1}$ Fundamental \& Applied Sciences Department, Universiti Teknologi PETRONAS, 32610 Bandar \\ Seri Iskandar, Perak \\ ${ }^{2}$ Chemical Engineering Department, Universiti Teknologi PETRONAS, 32610 Bandar Seri Iskandar, \\ Perak \\ ${ }^{3}$ Chemical Engineering Department, Universiti Teknologi PETRONAS, 32610 Bandar Seri Iskandar, \\ Perak \\ ${ }^{4}$ Civil Engineering Department, Universiti Teknologi PETRONAS, 32610 Bandar Seri Iskandar, \\ Perak \\ ${ }^{5}$ Mechanical Engineering Department, Universiti Teknologi PETRONAS, 32610 Bandar Seri \\ Iskandar, Perak \\ ${ }^{6}$ Petroleum Engineering Department, Universiti Teknologi PETRONAS, 32610 Bandar Seri \\ Iskandar, Perak
}

\begin{abstract}
A portable, non-electric washing machine powered by human leg identical to cycling is produced in order to fulfil the need of varsity students to wash their clothes in a cheap, eco-friendly and time saving and also to do physical body exercises. A black plastic bin has been used as the main body. At the bottom lies the rotating disk to provide agitation to the water and also cleaning the clothes. Shaft and gears are also been used in the rotating and moving mechanism that is connected to the pedal. This ecofriendly washing machine with an affordable price will benefit the lower income family and also for the college students.
\end{abstract}

\section{Introduction}

\subsection{Background}

Conventional washing machine generally is not eco-friendly. On average, $1 \mathrm{~kg}$ of clothes would take up to 10 liters of water in a conventional washing machine. An official measurement of energy efficiency for washing machines called the "energy factor" and measures how many cubic feet of washing can be accomplished per kilowatt-hour of electricity consumed [1]. The usage a lot of water for a few clothes can be of huge wastage. Therefore, this project is aimed to track these necessities and fulfill the requirement with the most suitable product which is a portable non-electric powered washing machine.

\footnotetext{
*Corresponding author: hamzah.sakidin@utp.edu.my
} 


\subsection{Objectives}

The objective of this project is given below:

1. To fulfil the need of varsity students to wash their clothes in a cheap, eco-friendly and time saving manner.

2. To do more physical body exercise while doing the laundry.

3. To give choice to lower income group for doing the laundry

\section{Literature Review}

Doing a laundry is an essential factor in human life. Since the first electric washing machine was invented by Alva J. Fisher in 1908, it had been benefit for people's lives [2]. However, the way they do it differs from one person to another according to their necessities.

Furthermore, according to a survey done all around Malaysia stated in Cuti-cuti Malaysia on 2014 which showed concerns raised against the use of public laundry services among young adults as many of them wished if they have a portable washing machines because they usually just wash their customer's clothes with less of detergent and use detergent of a low quality. They also put clothes over limit of the washing machine capacity, thus it causes the washing machines not to wash properly and cleanly. Another reason is related to workers mistakes in separating customer clothes in which result in missing some of these clothes [3].

In addition, designing a lightweight washing machine would settle the problem of homeowners with no extra room or small apartments such as studio apartments, and for people who travel frequently [4]. It is also suitable for operation in case of lack of water connection as well as for weekend riders and anyone who wants to wash quickly [6].

\section{Methodology}

Appropriate tools and selection of materials are important so that the prototype can be built smoothly and will not cause any trouble. An existing product is required to be modified to the extent of being able to insert a few elements for the mechanism to operate properly.

The planning and discussion of this project need to be done in a proper way to ensure the final prototype can be produced successfully.

The flow chart in Figure 1 shows the stages of the project from the initial stage to the final stage. 


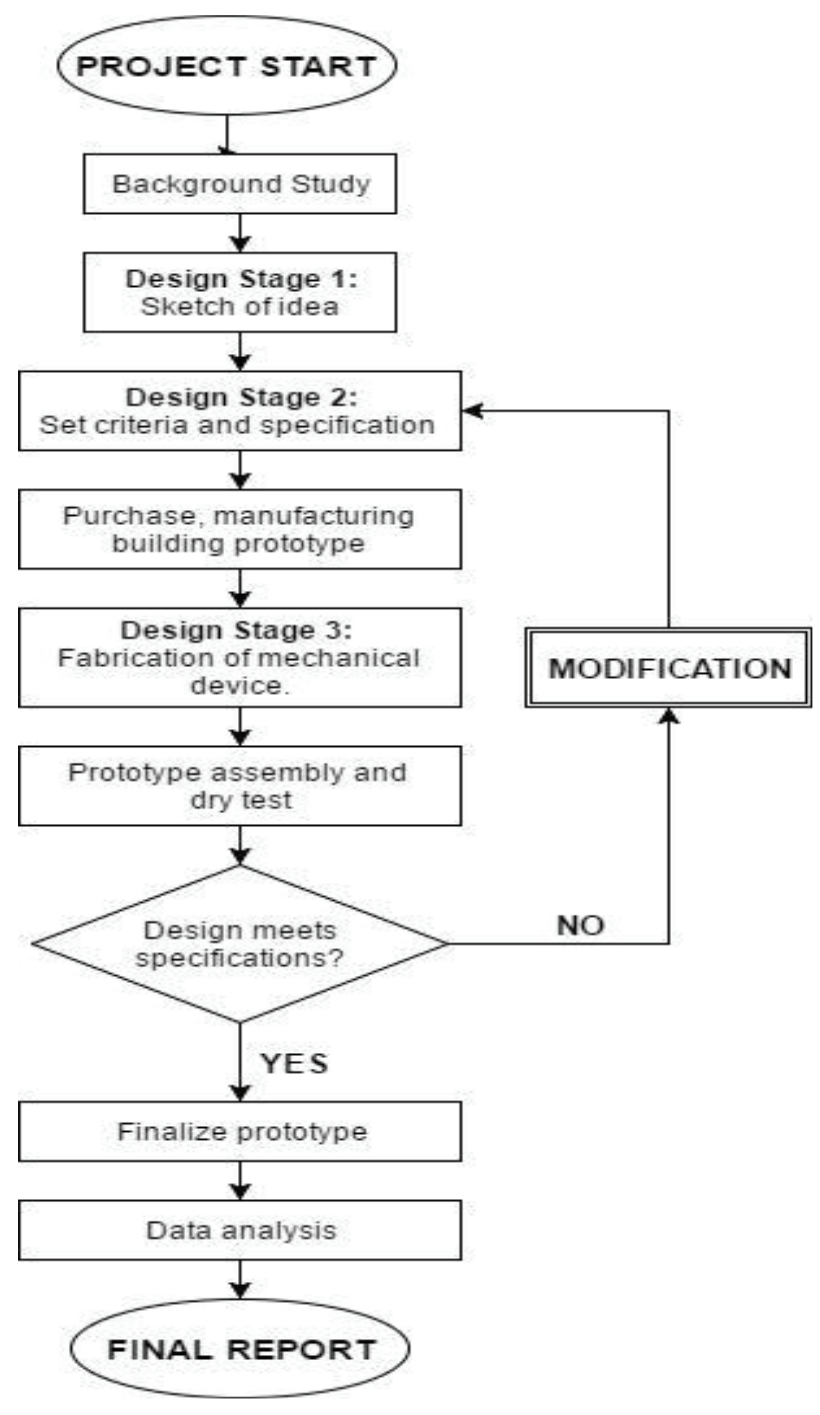

Fig. 1: Flow Chart of the project

\subsection{Concept of design}

This project is feasible and efficient design for our portable, non-electric washing machine. The main body of the washing machine consists of a cylindrical barrel or a bin. This barrel would be made of durable and sturdy plastic and polymer, like that of household pails.

This material is chosen for its overall economic value. A rotary base is attached to the bottom of the barrel; coaxially. This base is equipped with ridges or fins that functions as an agitator to promote the whirlpool motion of water in the device. The height of these ridges will be designed to be tall enough to create sufficient agitation and to avoid tangling up the clothes in the washing machine. 
Chain and gears will provide the rotation motion for the barrel. This mechanism will be powered by a paddle located at the side of the barrel. The paddle will spin a horizontal gear that is perpendicularly aligned with a horizontal gear. This horizontal gear acts as the connection between the main peddle and the rotary base. As this gear spins with the kinetic energy supplied by peddling, the rotary base will spin along with it, thus agitating the contents in the barrel. To ensure the spaces in between the gears, rotary base, and the bottom of the barrel are waterproof, they will be sealed off with either silicon seal or a rubber seal.

The entire peddling mechanism will be isolated at the bottom of the barrel in a hollow plastic enclosure, protecting it from external forces or disturbances. This enclosure will also act as a foundation for our washing machine. The designed is capped off with a durable plastic cover, equipped with fitting sockets to ensure the barrel is sealed tight when the washing commences. The water in the barrel can be disposed off simply by tilting the device over once the washing is done.

\subsection{Description of prototype material}

Below is the description of materials to be used for prototype in the design:

Table 1: Materials description

\begin{tabular}{|c|c|}
\hline Material & Description \\
\hline $\begin{array}{l}\text { Plastic bin } \\
\text { with cover }\end{array}$ & $\begin{array}{l}\text { Main prototype material. The clothes are loaded } \\
\text { in the plastic bin, where the clothes are washed. } \\
\text { The external tub covers the inner tub and supports } \\
\text { it during various cycles of clothes washing. }\end{array}$ \\
\hline $\begin{array}{l}\text { Rotary disk } \\
\text { with ridges }\end{array}$ & $\begin{array}{l}\text { The rotary disk is located inside the tub of the } \\
\text { washing machine. It is the important part of the } \\
\text { washing machine that actually performs the } \\
\text { cleaning operation of the clothes. During the } \\
\text { washing cycle the rotary disk rotates continuously } \\
\text { and produces strong rotating currents within the } \\
\text { water due to which the clothes also rotate inside } \\
\text { the tub. The rotation of the clothes within water } \\
\text { containing the detergent enables the removal of } \\
\text { the dirt particles from the fabric of the clothes. } \\
\text { Thus the rotary disk produces most important } \\
\text { function of rubbing the clothes with each other as } \\
\text { well as with water. }\end{array}$ \\
\hline Pedal & $\begin{array}{l}\text { User pushes the pedal using foot powered. The } \\
\text { pedal are connected to gear that will rotates the } \\
\text { rotary disk and form kinetic energy. }\end{array}$ \\
\hline Gears & $\begin{array}{l}\text { Transfer kinetic energy from pedal foot powered } \\
\text { to mechanical energy of the mechanism }\end{array}$ \\
\hline $\begin{array}{l}\text { Hollow } \\
\text { Plastic } \\
\text { Foundation }\end{array}$ & $\begin{array}{l}\text { Separates the mechanical part of the washing } \\
\text { including pedal, gears, shaft, bolts and nuts from } \\
\text { washing space. It can prevent water from seeping } \\
\text { into the mechanical part of the washing machine } \\
\text { that can cause rust. }\end{array}$ \\
\hline Shaft & $\begin{array}{l}\text { Transfer power from gears for rotation of the } \\
\text { rotary disk }\end{array}$ \\
\hline
\end{tabular}

The listed item in Table 1 are the things that used to build the prototype. A black plastic bin has been used as the main body. At the bottom lies the rotating disk to provide agitation. 
to the water and also cleaning the clothes. Shaft and gears are also been used in the rotating and moving mechanism that is connected to the pedal.

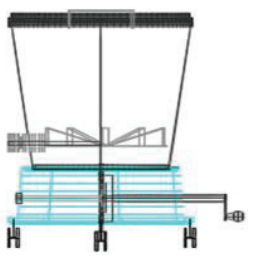

Fig 2a : Front view

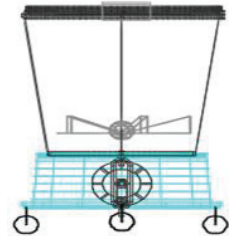

Fig 2b: Side view

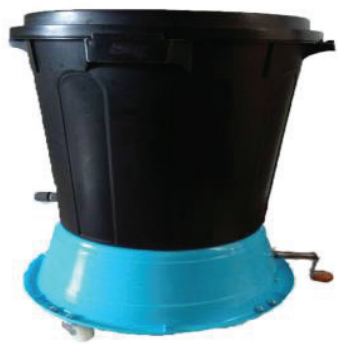

Fig 3: Prototype

Figure $2 \mathrm{a}$ and Figure $2 \mathrm{~b}$ show the schematic diagram of the eco-friendly washing machine. The prototype of the eco-friendly washing machine is given in Figure 3.

\section{Analysis}

\subsection{Survey data}

An online survey was conducted to 36 respondents from varsity students to identify the response for eco-friendly washing machine. Based on the survey, most of varsity students think that washing machine and laundryman service are expensive and inefficient. Washing machine and dryer services that are offered at their places need approximately RM 6 each time to operate and most of the students are doing laundry once a week. Mathematically, if we calculated it, one student would spend RM24 a month and RM 288 a year. Whereas, some of the self-service washing machine offered RM 10 cost each time to operate and that would have cost RM 480 a year.

Some students would prefer to wash their laundry manually by hand which would consumes energy and time. Therefore, there is a need to create a portable and a cheap alternative of doing laundry. Besides that, it would also save water and energy. It is foot pedal powered without using any electricity and would not be using too much water as the conservative washing machine nowadays. As for a small capacity of washing machine, this design prototype washing machine can be carried around with ease and very compact.

From the trial run, the consumption of water can be reduced from the usual 40 gallons to 9 gallons with this washing machine. These 9 gallons constitutes one wash for about 8 to 9 pieces of clothes. It shows that this prototype takes one gallon to wash one piece of clothing whereas a normal washing machine that can usually for around 20 pieces of clothing would 
use 2 gallons per clothing item. This is an improvement from the usual conventional electric washing machine.

Moreover, this prototype uses absolutely no form of electrical power as the hand powered washing machine which provides good exercise for the users. The mechanical gear system along with the hand paddle make up the operational system of our prototype, using the principles of kinetic energy. It registers 3 rotations of the rotary device per rotation of the handle. This gives us 225 rotations per minute of the device without water and $105 \mathrm{rpm}$ with water. Although it is much lesser than that of a normal washing machine, it is standard for a hand powered one and is enough to complete the washing of clothes.

\subsection{Costing}

The economical of the project is important to ensure the items and parts are under the budget allocated. In this project, the economic analysis covers the overall cost of the prototype and also the real product. With variety of products in the market, the price range for every component in the project is quite high, therefore it is crucial to choose the affordable one, yet can maintain the quality of the prototype build by our team. The cost of the prototype can be shown in Table 2.

Table 2 : Costing for the prototype

\begin{tabular}{|c|l|c|c|c|}
\hline No & \multicolumn{1}{|c|}{ Item } & Quantity & $\begin{array}{c}\text { Unit Price } \\
(\mathrm{RM})\end{array}$ & $\begin{array}{c}\text { Total Price } \\
(\mathrm{RM})\end{array}$ \\
\hline 1 & Barrel & 1 & 10 & 10 \\
\hline 2 & $\begin{array}{l}\text { Gear and } \\
\text { had drill set }\end{array}$ & 1 & 17 & 17 \\
\hline 3 & $\begin{array}{l}\text { Metal bar } \\
\text { including } \\
\text { welding }\end{array}$ & - & 50 & 50 \\
\hline 4 & $\begin{array}{l}\text { Rotating } \\
\text { base }\end{array}$ & 1 & 50 & 50 \\
\hline 5 & Basin & 1 & 6 & 6 \\
\hline 6 & $\begin{array}{l}\text { Bicycle tyre } \\
\text { rim }\end{array}$ & 1 & 14 & 14 \\
\hline 7 & wheels & 4 & $4.50 \times 4$ & 18 \\
\hline Total & \multicolumn{3}{|l}{} \\
\hline
\end{tabular}

Based on the costing above, may be the cost is quite expansive, however for the future purposes, the cost can be reduced after some modification on the prototype.

\section{Conclusion}

This project is a manual pedal-powered machine, thus it reduces electricity consumption in which decreases carbon footprint and that contributes to protecting our lovely globe from global warming.

More interestingly, this handy portable machine is designed to save money because all what it takes is just a good foot exercise in order to cut down on detergent usage and your electricity and water bills. Besides the materials selected to build the machine are cheap mainly plastic and steel, and the size is small as well as no electric parts or programming 
involved in the design process, increasing the chance of innovating a low-cost and competitive product.

Additionally, a normal electric washing takes 30-60 minutes per wash compared to the manual washing machine which only take 7 minutes to perform the duty.

The advantages of this washing machine are:

1. Portable

2. Can reduce carbon footage

3. Can reduce water usage

4. Good for hand muscle workout

5. Cheap

Overall, this washing machine do not require electrical components, so that it can last longer than traditional washing machines and never require maintenance or parts replacement.

The authors would like to acknowledge Universiti Teknologi PETRONAS (UTP) for financial assistance.

\section{References}

1 Foreman.G. (2011). "Your Washing Machine and the Environment". The Dollar Stretcher.com. [Online] Available: http://www.stretcher.com/stories/00/000911e.cfm

2. Barracuda (2015). "Who invented the Washing Machine?”. Service Force. [Online] Avaiable:

http://www.serviceforce.co.uk/blog/kitchen-appliances/who-invented-the-washingmachine/

3. Mamat, N. (2015). New Portable Washing Machine. [Online] Retrieved on May 27, 2015 [Online] Available :

https://www.essays24.com/History-Other/New-Portable-Washing-Machine/62265.html

4 Z, Kara. (2014). Living Direct: The Benefits of Portable Washers. [Online] Retrieved on May 9, 2014. [Online] Avaiable :

https:/learn.livingdirect.com/portable-washer-benefits/

5. N, Radojicic. (2010). The Advantages of Portable Washing Machines. [Online] Available: http://ezinearticles.com/?The-Advantages-of-Portable-Washing-Machines\&id=4551964

6. S. John. (2017). Portable Washing Machines: What are the Advantages and Disadvantages? [Online] Avaiable :

http://www.blogher.com/portable-washing-machines-what-are-advantages-and disadvantages 